\title{
DNA from microdissected tissues may be extracted and stored on microscopic slides
}

\author{
M. KORABECNA ${ }^{1,2, *}$, P. STEINER ${ }^{3}$, M. JIRKOVSKA ${ }^{4}$ \\ ${ }^{1}$ Institute of Biology and Medical Genetics, First Faculty of Medicine, Charles University in Prague and General Faculty Hospital in Prague, \\ Albertov 4, 12800 Prague, Czech Republic; ${ }^{2}$ Medical Faculty in Pilsen, Charles University in Prague, Husova 3, 30605 Pilsen, Czech Republic; \\ ${ }^{3}$ Bioptic Laboratory, Mikulasske nam. 628/4, 32600 Pilsen, Czech Republic; ${ }^{4}$ Institute of Histology and Embryology, First Faculty of Medicine, \\ Charles University in Prague and General Faculty Hospital in Prague, Albertov 4, 12800 Prague, Czech Republic
}

${ }^{*}$ Correspondence: marie.korabecna@lf1.cuni.cz

Received October 13, 2015 / Accepted November 26, 2015

With regard to complex structure of tissues, laser capture microdissection represents an important step in analytical workflow streaming to proper molecular characterization of different cell types in examined samples.

Therefore the simple method for simultaneous processing of higher numbers of microdissected tissues leading not only to rapid and efficient DNA isolation but allowing also the repeated sampling and easy storage may be useful in the practice of histopathological laboratories. We elaborated such a methodology applicable downstream after the microdissection from formalin-fixed paraffin embedded tissues.

The tissues for examination are microdissected directly into the circular areas having the diameter $2 \mathrm{~mm}$ and marked on the microscopic slide. In this way, one slide is able to accommodate multiple samples. The DNA extraction is performed in low volume of buffer with Proteinase $\mathrm{K}$ in a droplet covered by mineral oil just on the slide. Mineral oil in the quality for molecular biology not only avoids evaporation during DNA extraction, but it helps to position the microdisssected tissue, to control the level of cell lysis microscopically and to protect the DNA sample during subsequent manipulations. We provided the evidence that DNA isolated by our methodology remains in the positions on microscopic slide for months without any changes in the lengths of available fragments and that it may be removed from each position repetitively for different kinds of analysis. The new methodological approach presented by us can be practically applied in broad spectrum of laboratories performing routinely genetic analysis on microdissected tissues.

Key words: laser capture microdissection - FFPE tissue sections - DNA isolation -DNA storage - PCR

Each tissue contains different spatially distributed cell types together with extracellular matrix. Individual cells respond to physiologic and/or pathogenic stimuli dependently on their cell type and spatial localization inside the tissue. Numerous studies were performed using laser capture microdissection (LCM) to answer the questions concerning the biological differences between cells and cell-populations in tissues (reviewed in [1]).

Usually, DNA from limited amounts of microdissected biological material is isolated and stored in buffer solutions in plastic tubes. It is well known, that DNA samples could be subjected to acidic hydrolysis if stored in aqueous solutions, and DNA stability is dependent on its concentration and buffer composition [2]. As acidic conditions cause the DNA hydrolysis, the DNA is stored in aqueous solutions under slightly basic conditions (e.g. Tris-EDTA Buffer, pH 9).
Storage of DNA in dry state is an alternative - the dehydration reduces molecular mobility and in this manner it inhibits all DNA damaging reactions. Storage of DNA on FTA Cards (Whatman) has been successfully tested for fine-needle aspiration samples [3]. FTA cards are based on patented Whatman FTA technology. According to information provided by their manufacturer, these cards contain chemicals for cell lysis, protein denaturation and protection of nucleic acids from nucleases, oxidation and UV damage. FTA cards also rapidly inactivate microorganisms and prevent their growth.

The microscopic slides were tested only as a potential carrier of DNA molecules for the development of arrays technologies. It has been recognized, that the untreated microscopic slides are not suitable for irreversible DNA anchoring. The salmon DNA applied on such slides was subsequently washed out and 
the reaction kinetics was described in details under controlled experimental conditions [4].

The formaldehyde fixed-paraffin embedded (FFPE) tissues belong to the most common material examined in histopathological laboratories. By this reason, we developed a method with the application of Proteinase K treatment for disruption of covalent bounds arising as a consequence of formaldehyde fixation [5].

We present the new method connecting the microdissection, DNA isolation, DNA storage and repeated DNA sampling together with an easy handling and space-saving format suitable also for interlaboratory exchange. The microdissected tissues (e.g. selected to contain only tumor cells) from different samples may be placed on the microscopic slide with 48 circular positions and extracted simultaneously. The completeness of the lysis is then microscopically controlled. After complete lysis, each DNA sample in each position on slide is prepared to be removed from the slide repetetively for different types of DNA based analysis. The procedure allows simultaneous operations on multiple micriodissected pieces of tissues that may be subjected consequently to different DNA based examinations.

\section{Material and methods}

For the preparation of microdissected tissue samples, a FFPE sample of papillary renal cell carcinoma was used. $4 \mu \mathrm{m}$ sections were applied on the Frame Slides (PET membrane, $1.4 \mu \mathrm{m}$, Leica), H \& E stained and used for microdissection (Laser Capture Microdissection, LMD 6500, Leica). For microdissection, the homogenous areas of tumor tissue, $0,2 \mathrm{~mm}^{2}$ in size were selected and just during the microdissection process they were placed into circular positions having average $2 \mathrm{~mm}$ and marked on the AmpliGrid slide (Advalytix) (Figure 1). The slides were used without any pretreatments. One slide accommodates 48 microdissected pieces of the tissue, each one in its own position.

After microdissection, DNA was isolated from all positions on the slide as follow: Lysis buffer was prepared immediately before the use - Proteinase $\mathrm{K}$ solution $(20 \mathrm{mg} / \mathrm{ml}$ in $20 \mathrm{~m}$ MTris- $\mathrm{HCl}, 1 \mathrm{mM} \mathrm{CaCl}$, 50\% glycerol, $\mathrm{pH}=7,3$, Qiagen) was diluted $1: 3$ in $30 \mathrm{mM}$ Tris- $\mathrm{HCl}, \mathrm{pH}=8$. To each circular position with microdissected tissue, $2 \mu \mathrm{l}$ of this lysis buffer were added. The droplets containing microdissected tissues in lysis buffer were completely covered by $5 \mu$ l of mineral oil (quality for molecular biology). The slide was incubated 1 hour at $56{ }^{\circ} \mathrm{C}$ to digest the tissue and then $5 \mathrm{~min}$ at $95^{\circ} \mathrm{C}$ to denature the Proteinase K. After the heat inactivation of Proteinase K, the half amount of mineral oil has been removed to facilitate the drying of aqueous phase on the slide at $56^{\circ} \mathrm{C}$. Mineral oil was removed by pipetting - interphase between the aqueous solution and oil is clearly visible therefore there is no risk for the loss of the DNA sample. The geometry of circular positions on the slides is designed to keep small volumes of liquids in place. The slide design and minimal liquid volumes used in this methodology minimize the risk of cross-contamination between the positions on the slide. For drying in an incubator, the slide was placed into an open sterile plastic microscope slide mailer designed for transport of 5 microscope slides. After drying, the box may be closed and used for the storage of the slide in horizontal position without the risk of contamination. The slide mailer has a hinged lid on its short side which is closed tightly to prevent the slide from accidentally falling out.

After drying, the slide was ready for storage at $4^{\circ} \mathrm{C}$ and repeated DNA samples collection and DNA quality testing in 14 days intervals. For DNA collection from one position, $5 \mu \mathrm{l}$ of buffer (30 mM Tris- $\mathrm{HCl}, \mathrm{pH}=8$ ) were added to this position, incubated $30 \mathrm{~s}$ at room temperature and then removed and placed into a PCR tube.

DNA integrity in such samples was examined according to the method published by van Dongen et al. [6]. The multiplex PCR reaction is designed to produce amplicons of sizes ranging from $100 \mathrm{bp}$ to $600 \mathrm{bp}$ and to provide the evidence that the DNA in the examined sample is suitable for further molecular genetic analysis in a histopathology laboratory. The amplified genes, primers and lengths of amplicons are given in Table 1. PCR reaction were carried out in the total volume of $25 \mu$ l containing $10 \mu \mathrm{l}$ Fast Start Master Mix (Roche), $0.4 \mu \mathrm{l}$ $25 \mathrm{mM} \mathrm{MgCl}_{2}$ solution, $0.48 \mu \mathrm{l}$ Primer Mix (10 pmol of each primer), $9.12 \mu \mathrm{l}$ water for injections and $5 \mu \mathrm{l}$ DNA sample. All reactions were run on the 2720 Thermal Cycler (Applied Biosystems) using the following thermal profile: initial dena-

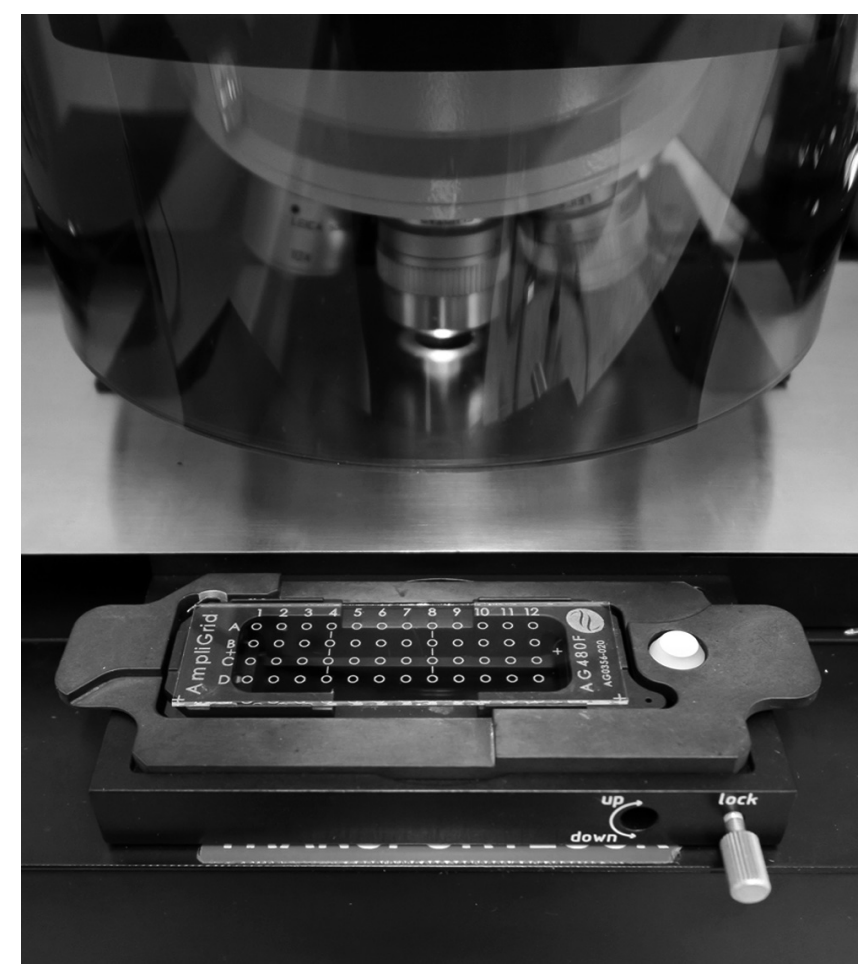

Figure 1. AmpliGrid slide prepared for insertion into the instrument for laser capture microdissection (LMD 6500, Leica). 
Table 1. Amplified genes, primers and amplicon lengths used for DNA integrity examination according to van Dungen et al. (2003)

\begin{tabular}{lll}
\hline Gene & Forward primer & Reverse primer \\
\hline TBXAS1 & GCCCGACATTCTGCAAGTCC & GGTGTTGCCGGGAAGGGTT \\
RAG1 & TGTTGACTCGATCCACCCCA & TGAGCTGCAAGTTTGGCTGAA length (bp) \\
$P L Z F$ & TGCGATGTGGTCATCATGGTG & CGTGTCATTGTCGTCTGAGGC \\
AF4 exon 11 & CCGCAGCAAGCAACGAACC & GCTTTCCTCTGGCGGCTCC \\
AF4 exon 3 & GGAGCAGCATTCCATCCAGC & CATCCATGGGCCGGACATAA \\
\hline
\end{tabular}

turation at $95^{\circ} \mathrm{C}$ for $14 \mathrm{~min}, 35$ cycles consisting of $95^{\circ} \mathrm{C}$ for $1 \mathrm{~min}, 60^{\circ} \mathrm{C}$ for $1 \mathrm{~min}, 72^{\circ} \mathrm{C}$ for $1.5 \mathrm{~min}$ and the final extension at $72^{\circ} \mathrm{C}$ for $7 \mathrm{~min}$. The DNAs isolated by DNA Mini Kit (Qiagen) according to the manufacturer instructions from fresh blood of a volunteer and also directly from the paraffin sections of the examined FFPE sample served as the positive controls, water for injection was used as the negative control. Due to the archive character of the examined FFPE tissue, the DNA isolated from this material was used only for the initial comparison. In further experiments the DNA isolated from blood of a healthy donor was amplified as positive control for multiplex PCR performance. The amplified fragments were analyzed on $2 \%$ agarose gels.

After 3 months of DNA storage on slide, the DNA samples for forensic analysis were collected as described above and subjected to analysis with the kit PowerPlex ESI 17 (Promega) intended for routine use in forensic laboratories and allowing exact individual identification. The kit was used in agreement with manufacturer recommendation, the results of multiplex STR (short tandem repeats) amplification were analyzed on ABI PRISM 310 Genetic Analyzer (Applied Biosystems).

\section{Results}

The role of mineral oil in the workflow was studied with regard to the control of proper digestion of microdissected tissues (Figure 2). The mineral oil left on slide allowed the microscopic control of the completeness of digestion and helped to keep the microdissected material in the position in horizontal orienta- tion to prevent its loss during manipulation with the slide. If microscopic control would detect a non-complete digestion of microdissected tissue the digestion step may be repeated.

The FFPE sample for analysis was selected due to its exceptional DNA integrity which is not generally achieved when working with such types of samples. The successful amplification of fragments having the maximal length of $200 \mathrm{bp}$ is usually awaited in such cases [7]. The samples examined by us allowed amplification of the $600 \mathrm{bp}$ fragments in multiplex PCR but with lower effectivity than the shorter fragments as demonstrated in Figure 3A. The DNA isolated directly from the examined FFPE sample provided after amplification similar electrophoretic pattern as the DNA from the same sample isolated after microdissection on slide (Figure 3A). This comparison excluded the effect of additional PCR inhibitors which could eventually be recruited due to the slide based DNA isolation procedure and it provided the evidence that the weaker amplification of the longest fragment represents the condition of the FFPE sample itself. With regard to archive character of examined FFPE tissue, the DNA isolated from the blood of a healthy volunteer was used as a less valuable material in following experiments.

DNA isolation from all examined microdissected tissues on 48 positions on the slide was successful in $100 \%$. Figure 3 documents the sufficient integrity of DNA samples after 3 month of storage and after repeated DNA removal from the same position. DNA samples from 24 positions were collected at least two times. The repeatedly collected samples provided satisfactory results after the fourth removal from
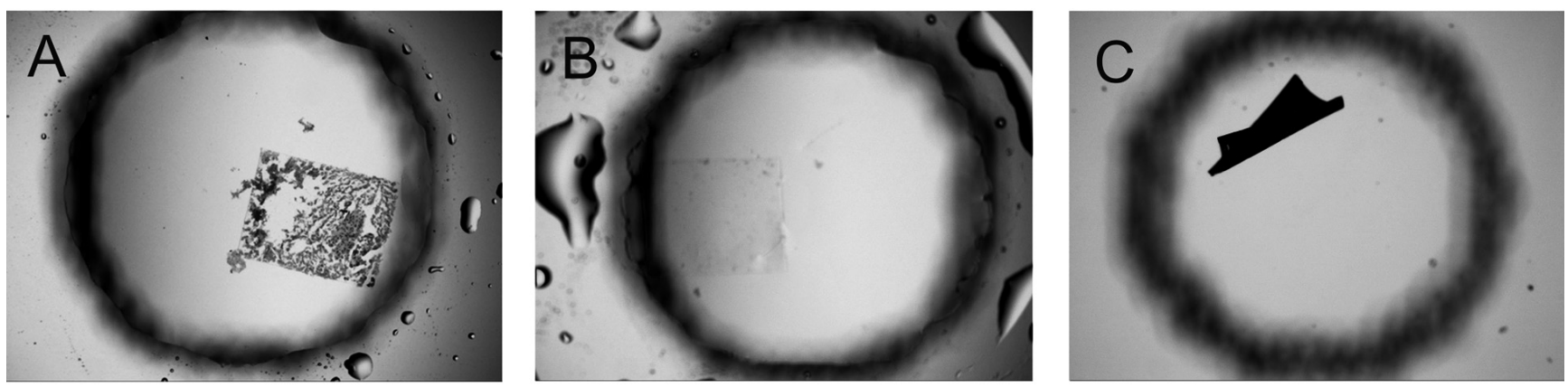

Figure 2. The role of mineral oil in the workflow. Microscopic control of microdissected tissue after Proteinase K digestion ( A and B - droplet of mineral oil covers the circular position on the slide, $\mathrm{A}$ - partial tissue digestion, $\mathrm{B}$ - complete tissue digestion, $\mathrm{C}$ - a position without the mineral oil, the $\mathrm{PET}$ membrane with microdissected tissue is not hold in horizontal position) 
A

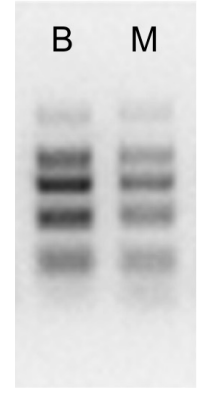

B

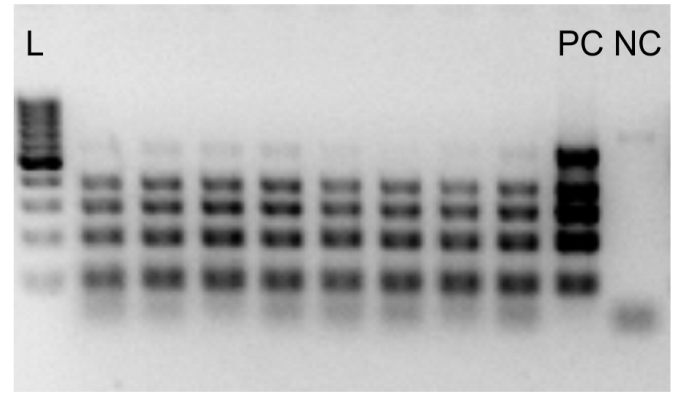

C

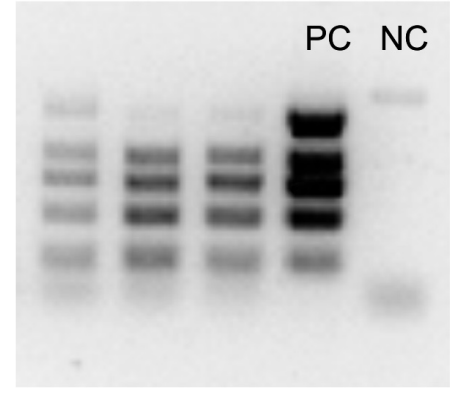

Figure 3. DNA integrity of DNA samples examined according to the method described by van Dongen [6]. Amplified fragments were separated on $2 \%$ agarose gels. A - comparison of DNA isolated directly from the FFPE sample and DNA isolated after microdissection on the slide from the same sample (B - $5 \mu \mathrm{l}$ of PCR products amplified from DNA isolated directly from the FFPE tissue, $\mathrm{M}-15 \mu \mathrm{l}$ of PCR products amplified from DNA isolated on slide from microdissected material), B - integrity of 8 samples immediately after the isolation on the slide, $\mathrm{C}$ - the integrity of a sample after the thirth DNA removal (the first line) and integrity of two samples removed from the slide first time after 3 months of storage (the second and the third line). $\mathrm{L}-100 \mathrm{bp}$ DNA ladder, PC - positive control (600 bp band on the top of gel), NC - negative control. $15 \mu \mathrm{l}$ of PCR products amplified from DNA isolated on slide from microdissected material and $5 \mu \mathrm{l}$ of PCR products amplified from DNA isolated from blood of healthy volunteer were loaded on gels.

the same position, but after the $5^{\text {th }}$ DNA removal, $30 \%$ of our samples ( 4 out of 12 analyzed) show results comparable with non-template control at the level of multiplex end-point PCR performed as described above.

After 3 months of storage the DNA was removed from five positions and each sample was subjected to forensic identification using multiplex PCR allowing amplification of 17 polymorphic STR loci. The results of such an individual identification of the donor of examined tissue are summarized in Table 2. The complete profiles were obtained. The profiles of all researchers and laboratory staff were compared to the profile of the donor of examined tissue to avoid misinterpretation due to laboratory contamination.

According to the allele frequencies reported for the Czech population [8] and according to the population data provided by Promega (www.promega.com), we calculate the probability of the coincidence of this unique profile of our tissue donor with a profile of randomly selected person as 5 persons out of $10^{24}$ individuals.

\section{Discussion}

Tissue biodepositories represent one of the most important sources of biological material for translational research in biomedicine [9]. The method documented in this article could provide a new handy tool for genetic analysis of tissues retrieved from such biodepositories.

The use of FTA cards for storage of breast carcinoma nucleic acids from fine-needle aspiration samples was described by Peluso et al. [3]. This method is not suitable for work with material microdissected from FFPE samples but it is based also on the storage of dried DNA samples. Our method is easy to perform, it uses mineral oil not only as a barrier against evaporation during tissue digestion process, but also for facilitation of microscopic control and as prevention against access of humidity to the stored DNA sample which is bound reversible to the glass surface.

The number of potentially possible repeated DNA removals from the same position on the slide will certainly be dependent on the cellularity and on the size of the microdissected tissue. We selected the tumor tissue with high DNA integrity and cellularity for our pilot experiments. We provided the evidence that the method is functional for such samples and that it ensures the successful recovery of DNA fragments of lengths they are expected when working with FFPE samples.

The AmpliGrid slides used in our pilot study were originally developed for single-cell small volume PCR performed just in 2 $\mu \mathrm{l}$ of reaction mixture placed on each separated cell localized in

Table 2. Results of individual identification of the donor of microdissected tissue. The numbers give the repetitions of short tandem repeats of the examined STR polymorphic loci on individual chromosomes. Examination of amelogenin gene $(A M E L)$ sequences allows the sex determination.

\begin{tabular}{|c|c|c|c|c|c|c|}
\hline Locus & $A M E L$ & D3S1358 & D19S433 & D2S1338 & D22S1045 & $D 16 S 539$ \\
\hline Genotype & $\mathrm{XX}$ & 15,17 & 14,15 & 23,26 & 12,12 & 11,12 \\
\hline Locus & D18S51 & D1S1656 & D10S11248 & D2S441 & THO1 & $v W A$ \\
\hline Genotype & 14,15 & $15,17.3$ & 13,13 & $11.3,11.3$ & 6,8 & 15,17 \\
\hline Locus & D21S11 & D12S391 & D8S1179 & $F G A$ & SE33 & \\
\hline Genotype & $28,30.2$ & $18,18.3$ & 11,13 & 20,23 & $15,26.2$ & \\
\hline
\end{tabular}


its own circular position on the slide and covered by mineral oil to prevent the evaporation during cycling performed on special PCR cycler constructed to accommodate these slides (see e.g. [10]). Our methodology takes advantage of the possibility to accommodate the AmpliGrid slide or a slide of identical size in the instrument for laser capture microdissection (Leica) (Figure 1). We can microdissect the selected areas of tissues just on the surface of the slide and subsequently subject them to our workflow. In this manner, we obtain more DNA aliquots from the identical microdissected tissue and such aliquots may serve for different DNA based analysis without any need to repeat the time consuming microdissection step and without the risk of acidic hydrolysis of DNA samples of low concentration in aqueous solution.

We described in presented paper a new methodology for dry storage of DNA samples from microdissected tissues allowing easy and simultaneous handling of multiple samples which may be subjected to a flexible laboratory workflow consisting e.g. of more subsequent PCR reactions.

Using the methodology which is established in forensic genetics, we documented that our methodology - if properly performed - is not susceptible to contamination by DNA from external sources.

Acknowledgements: Supported by the grant TIP I/328 of the Ministry of Industry and Trade of the Czech Republic, by the grant no. PRVOUK P25/LF1/2 of the Ministry of Education, Youth and Sport of the Czech Republic, and by the grant no. RVO-VFN 64165 of the Ministry of Health of the Czech Republic.

The authors thank A. Zidkova, $\mathrm{PhD}$ for the technical assistance in forensic identification.

\section{References}

[1] DATTA S, MALHOTRA L, DICKERSON R, CHAFFEE S, SEN CK et al.). Laser capture microdissection: Big data from small samples. Histol Histopathol. 2015; Apr 20: 11622. [Epub ahead of print]
[2] RODER B, FRUHWIRTH K, VOGL C, WAGNER M, ROSSMANITH P. Impact of long-term storage on stability of standard DNA for nucleic acid-based methods. J. Clin. Microbiol. 2010; 48: 4260-4262. http://dx.doi.org/10.1128/ LCM.01230-10

[3] PELUSO AL, CASCONE AM, LUCCHESE L, COZZOLINO I, IENI A et al. Use of FTA cards for the storage of breast carcinoma nucleic acid on fine-needle aspiration samples. Cancer Cytopathol. 2015; [Epub ahead of print] http://dx.doi. org/10.1002/cncy.21577

[4] NANASSY OZ, HAYDOCK PV, REED MW. Capture of genomic DNA on glass microscope slides. Anal. Biochem. 2007; 365: 240-245. http://dx.doi.org/10.1016/j.ab.2007.03.017

[5] GILBERT MT, HASELKORN T, BUNCE M, SANCHEZ JJ, LUCAS SB et al. The isolation of nucleic acids from fixed, paraffinembedded tissues-which methods are useful when? PLoS One; 2007; 2, e537. http://dx.doi.org/10.1371/journal.pone.0000537

[6] VAN DONGEN JJ, LANGERAK AW, BRUGGEMANN M, EVANS PA, HUMMEL $M$ et al. Design and standardization of PCR primers and protocols for detection of clonal immunoglobulin and T-cell receptor gene recombinations in suspect lymphoproliferations: report of the BIOMED-2 Concerted Action BMH4-CT98-3936. Leukemia 2003; 17: 2257-2317. http://dx.doi.org/10.1038/sj.leu.2403202

[7] ALVAREZ-ALDANA A, MARTINEZ JW, SEPULVEDAARIAS JC. Comparison of five protocols to extract DNA from paraffin-embedded tissues for the detection of human papillomavirus. Pathol Res. Pract. 2015; 211: 150-155. http:// dx.doi.org/10.1016/j.prp.2014.10.011

[8] SIMKOVA H, FALTUS V, MARVAN R, PEXA T, STENZL $\mathrm{V}$ et al. Allele frequency data for 17 short tandem repeats in a Czech population sample. Forensic Sci. Int. Genet. 2009; 4: e15-17. http://dx.doi.org/10.1016/j.fsigen.2009.01.003

[9] LIU A. Laser capture microdissection in the tissue biorepository. J. Biomol. Tech. 2010; 21: 120-125.

[10] BRUCK S, EVERS H, HEIDORN F, MULLER U, KILPER R et al. Single cells for forensic DNA analysis-from evidence material to test tube. J Forensic Sci. 2011; 56: 176-180. http:// dx.doi.org/10.1111/j.1556-4029.2010.01553.x 